\title{
CONIZATION, FROZEN SECTION EXAMINATION, AND PLANNED HYSTERECTOMY IN THE TREATMENT OF HIGH-GRADE CERVICAL INTRAEPITHELIAL NEOPLASIA
}

Jesus Paula Carvalho, Filomena Marino Carvalho, Katia Maciel Pincerato and Elsa A. Gay Pereyra

RHCFAP/3056

CARVALHO JP et al. - Conization, frozen section examination, and planned hysterectomy in the treatment of high-grade cervical intraepithelial neoplasia. Rev. Hosp. Clín. Fac. Med. S. Paulo 56(6):169-172, 2001.

Purpose: We tested the role of frozen section examination of the cone specimen in the evaluation of the resection margin status and to rule out invasion in patients with high-grade cervical intraepithelial neoplasia.

Methods: Twenty-five patients with cervical intraepithelial neoplasia underwent conization followed by frozen section examination and planned hysterectomy. The results of the definitive paraffin exam were compared with frozen section examination.

Results: In the evaluation of the margins by frozen section examination, 16 patients (64\%) had positive cone margins and 9 $(36 \%)$ had negative margins. The definitive paraffin examination of margin status was concordant in all the cases. Intraoperative diagnosis of invasion was made in 5 cases, and 1 of these was microinvasive. Among the remaining 20 cases, we detected 2 additional microinvasive carcinomas after paraffin study, so the diagnosis of the frozen section examination was concordant with the paraffin sections in 23/25 cases (92\%). Two cases of microinvasive carcinoma were diagnosed as cervical intraepithelial neoplasia by frozen section examination and had less than $2 \mathrm{~mm}$ stromal invasion.

Conclusions: In high-grade cervical intraepithelial neoplasia, frozen section examination can provide immediate and precise evaluation of the cone margin status in high-grade cervical intraepithelial neoplasia. It can identify frank invasion and permit adequate treatment in a one-stage procedure. In early microinvasive disease, frozen section examination fails to detect the area of invasion but reliably detects clear resection margins.

DESCRIPTORS: Cervical neoplasia. Intraepithelial neoplasia. Frozen section examination. Cervical conization. Hysterectomy.

High-grade cervical intraepithelial neoplasia (CIN 3) is the last step of neoplastic transformation in the cervical epithelium before invasion occurs. An inadequate or insufficient treatment can result in poor prognosis and death.

The treatment strategies for CIN have changed considerably in the last decades, moving from the classical surgical conization to office procedures such as large loop excision of the transformation zone (LLETZ) $)^{1,2}$. However, incomplete excision of CIN continues to be the most vulnerable point of this kind of treatment ${ }^{3-4}$.

Incomplete excision of CIN ranges from $15 \%$ to $50 \%{ }^{5-6}$ and presents a significant problem if follow-up is insufficient. Unfortunately, the disease progresses to invasive carcinoma in

From the Department of Dermatology, Hospital das Clínicas, Faculty of Medicine, University of São Paulo. many patients after an incomplete treatment for CIN.

In Brazil, women from very distant places are referred to Hospital das Clinicas for treatment of many diseases. We use this opportunity for screening them for cervical cancer and its precursor lesions.

We know most of these patients have only one chance for treatment of CIN, because they have to return soon to their homes where there is no adequate fol- 
low-up. Our policy is to choose the most efficient kind of treatment with least probability of recurrence.

For young patients with satisfactory colposcopy, the treatment of choice is large loop excision of the transformation zone (LLETZ). On the other hand, for older patients with large lesions, endocervical involvement, or suspicion of invasion, the classic surgical conization is a better option. In this high-risk group of patients, we tested the role of frozen section examination (FSE) of the cone specimen in order to evaluate the margin status and to rule out invasion, thus providing adequate treatment in a one-stage procedure.

Little attention has been paid to the role of FSE in cervical intraepithelial neoplasia. Some authors have demonstrated high concordance with the definitive paraffin exam in grading the lesion, but there are few studies regarding the evaluation by FSE of the resection margin status ${ }^{7-8}$.

\section{METHODS}

We studied prospectively 25 consecutive patients who underwent conization and planned hysterectomy who had the histological diagnosis of cervical intraepithelial squamous neoplasia grade 3 (CIN 3) and concomitant benign gynecologic disease, such as leiomyoma, abnormal uterine bleeding, or extensive CIN with suspicion of invasion. Patient ages ranged from 24 to 69 years, median 42 years. In these cases, particularly those with suspicion of invasion, the objective of the FSE was to evaluate the extent of invasion, thus permitting the adequate treatment of invasive carcinoma. Our second objective was to verify the accuracy of the FSE for evaluating the resection margin status.

We performed cold knife conization under general anesthesia, carefully excising the entire visible lesion. The vertical size of the cone ranged from $1 \mathrm{~cm}$ to $2.5 \mathrm{~cm}$.

The cone specimens were excised in one piece and sent immediately for FSE. The pathologist inked the cone with different colors in order to identify the anterior and posterior borders. The endocervical margin was selected for frozen section (Fig. 1). The remaining specimen was sectioned sequentially into $3-\mathrm{mm}$ pieces.

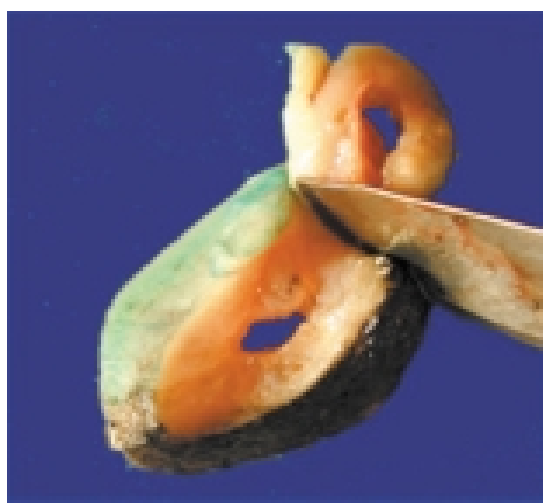

Figure 1 - Section of the endocervical margin for frozen section examination.

The pathologist selected for FSE the fragments corresponding to the grossly suspicious areas noted in the colposcopic image. The fragments not undergoing frozen section were processed in the traditional paraffin-embedded method, with inclusion of the entire material for histological examination.

In the patients with the diagnosis of invasion from FSE, the treatment was radical hysterectomy with pelvic lymphadenectomy (Wertheim-Meigs surgery). In those without signs of invasion, we performed a simple hysterectomy.

Table 1 - Comparison of intraoperative diagnosis by frozen section examination (FSE) and definitive paraffin exam.

\begin{tabular}{llrr}
\hline FSE & Definitive exam & $\mathrm{N}$ & $\%$ \\
\hline Absence of lesion & Absence of lesion & 2 & 8 \\
CIN & CIN & 16 & 64 \\
CIN 3 & Microinvasive & 2 & 8 \\
Microinvasive & Microinvasive & 1 & 4 \\
Invasive & Invasive & 4 & 16 \\
\hline TOTAL & & 25 & 100 \\
\hline
\end{tabular}

The results of the definitive paraffin exam were compared with those of the FSE. We evaluated the accuracy of the diagnosis of invasion and the resection margin status. The complementary specimen from the hysterectomy was studied in order to determine the presence of residual disease and its relation with the final diagnosis from the cone specimens.

\section{RESULTS}

Intraoperative diagnosis of invasion was made in 5 cases; 1 of these was microinvasive, and all were confirmed in the definitive diagnosis. Among the remaining 20 cases, we detected 2 additional microinvasive carcinomas after paraffin study; therefore, the diagnosis of the FSE was concordant with the permanent sections in $23 / 25$ cases $(92 \%)$ (Table 1). The 2 cases of microinvasive carcinoma diagnosed as CIN 3 by FSE had less than $2 \mathrm{~mm}$ of stromal invasion.

In the 4 cases of invasive carcinoma, FSE allowed us to identify the invasion and perform a radical hysterectomy with lymphadenectomy (Wertheim-Meigs surgery) in the same surgical procedure. One of these cases was the youngest patient (24 years old).

In the evaluation of cone margins by FSE, 16 patients $(64 \%)$ had positive surgical margins (Fig. 2) and 9 (36\%) had negative margins. There were 1 lateral and 15 endocervical margins involved. The definitive paraffin examination of margin status was concordant in all cases (Table 2). 
In the 16 cases with positive margins, we found residual disease in the uterus in $11(68.8 \%)$. In all cases of negative resection margins, the uterus did not have lesions (Table 3).

\section{DISCUSSION}

The two most undesirable occurrences following conservative CIN treatment are positive margins and undiagnosed invasive disease. In these two situations, the treatment is considered incomplete and the risk of recurrence is very high ${ }^{8}$.



Figure 2 - Positive endocervical margin with CIN 3 involving the superficial epithelium of the endocervical margin and the subjacent endocervical gland (hematoxylin-eosin-original magnification 100X).

Table 2 - Margin status by frozen section examination and definitive paraffin exam.

\begin{tabular}{lrrrrrrr}
\hline & \multicolumn{2}{c}{ Frozen section exam } & & \multicolumn{2}{c}{ Total } \\
\cline { 2 - 5 } Definitive exam & \multicolumn{2}{c}{ Positive margins } & \multicolumn{2}{l}{ Negative margins } & & \\
\cline { 2 - 6 } & $\mathrm{n}$ & $\%$ & $\mathrm{~N}$ & $\%$ & $\mathrm{n}$ & $\%$ \\
\hline Positive margins & 16 & 100 & 0 & 0 & 16 & 64 \\
Negative margins & 0 & 0 & 9 & 100 & 9 & 36 \\
\hline Total & 16 & 100 & 9 & 100 & 25 & 100 \\
\hline
\end{tabular}

Table 3 - Relationship between cone margin status and residual disease in uterus.

\begin{tabular}{|c|c|c|c|c|c|c|}
\hline \multirow{3}{*}{$\begin{array}{l}\text { Residual disease } \\
\text { in uterus }\end{array}$} & \multicolumn{4}{|c|}{ Frozen section cone margins status } & & \\
\hline & \multicolumn{2}{|c|}{ Positive } & \multicolumn{2}{|c|}{ Negative } & \multicolumn{2}{|c|}{ Total } \\
\hline & $\mathrm{n}$ & $\%$ & $\mathrm{~N}$ & $\%$ & $\mathrm{n}$ & $\%$ \\
\hline Absent & 5 & 31.2 & 9 & 100 & 14 & 56 \\
\hline Present & 11 & 68.8 & 0 & 0 & 11 & 44 \\
\hline Total & 16 & 100 & 9 & 100 & 25 & 100 \\
\hline
\end{tabular}

The adoption of FSE provides a solution for the two vulnerable points in the treatment of high-risk CIN. First, the lesion can be shown to have been entirely removed when negative cone margins are found; second, the diagnosis of invasive carcinoma can be made with good accuracy and treated adequately in a one-stage procedure.

Our study showed a high level of tumor involvement at the cone margins in extensive CIN 3 (64\%). Others have noted the frequent occurrence of positive resection margins in cervical conizations, particularly in the endocervical conizations ${ }^{9}$. Using FSE, we were able to accurately diagnose the resection margin status of all of our cases.

Eleven out of 16 patients with positive resection margins had residual disease in the uterus, and they probably would have been of high risk of recurrence if management had been expectant.

Using FSE, we were able to identify all 4 cases of invasive carcinoma, but only 1 of the 3 microinvasive cases. The 2 underdiagnosed cases had an invasion of less than $2 \mathrm{~mm}$. However, these lesions have a low risk of metastasis and can be treated as CIN with good results if the resection margins are clear.

\section{CONCLUSION}

FSE can provide immediate and precise evaluation of the cone margin status in high-grade CIN. It can identify frank invasion, permitting adequate treatment in a one-stage procedure. In early microinvasive disease, FSE fails to correctly grade the lesion, but FSE reliably detects clear resection margins. We believe FSE should be included in the treatment plan of women with high risk of tumor involvement in resection margins and who cannot participate an adequate follow-up. 
CARVALHO J P e col. - Conização, exame de congelação e histerectomia planejada no tratamento de neoplasia intra-epitelial de alto grau. Rev. Hosp. Clín. Fac. Med. S. Paulo 56(6):169-172, 2001.

Objetivos: Foi avaliado o papel do exame intra-operatório de congelação no diagnóstico de invasão e no estado das margens cirúrgicas em pacientes com neoplasia intra-epitelial de alto grau.

Casuística e Método: Vinte e cinco pacientes com neoplasia intraepitelial de alto grau foram submetidas a conização cervical seguida de histerectomia. $\mathrm{O}$ resultado do exame defi- nitivo em parafina foi comparado com o exame de congelação.

Resultados: Dezesseis pacientes (64\%) tiveram margens comprometidas e 9 (36\%) livres. O diagnóstico definitivo na parafina foi concordante em todos os casos no diagnóstico do estado das margens. Em cinco casos foi diagnosticada invasão, sendo 1 caso de carcinoma microinvasivo. Entre os 20 casos restantes foram detectados 2 carcinomas microinvasivos adicionais após o exame em parafina. Desta forma o exame intra-operatório de congelação foi concordante com o exame definitivo em 23/25 casos ( $92 \%$ ). Dois casos de carcinoma microinvasivo foram diagnosticados como neoplasia intra-epitelial de alto grau no exame de congelação e apresentavam invasão estromal menor que $2 \mathrm{~cm}$.

Conclusões: $\mathrm{O}$ exame intra-operatório de congelação é capaz de predizer o estado das margens cirúrgicas em todos os casos de neoplasia intra-epitelial de alto grau assim como o diagnóstico de invasão franca. Nos casos de carcinoma microinvasivo este exame falha na detecção de invasão, entretanto é capaz de garantir margens livres de ressecção.

DESCRITORES: Carcinoma de células escamosas. Neoplasia intraepitelial escamosa. Exame de congelação. Conização cervical. Histerectomia.

\section{REFERENCES}

1. JONES HW - Treatment of cervical intraepithelial neoplasia. Obstet Gynecol 1990;33:826-836.

2. WRIGHT TC JR, GAGNON S, RICHART RM et al. - Treatment of cervical intraepithelial neoplasia using the loop electrosurgical excision procedure. Obstet Gynecol 1992;79:173-178.

3. LUBICZ S, EZEKWECHE C, ALLEN A et al. - Significance of cone biopsy margins in the management of patients with cervical neoplasia. J Reprod Med 1984;29:179-184.

4. TOWNSEND DE - Cervical cone margins as a predictor for residual dysplasia in post-cone hysterectomy specimens. Obstet Gynecol 1994;84:898.

5. BALDAUF JJ, RITTER J, CUENIN C et al. - Therapeutic results of conization with diathermy. Contracept Fertil Sex 1999;27:140146.
6. CHAN KS, YU KM, LOK YH et al. - Conservative management of patients with histological incomplete excision of cervical intraepithelial neoplasia after large loop excision of transformation zone. Chin Med J 1997;110:617-619.

7. HANNIGAN EV, SIMPSON JS, DILLARD JR et al. - Frozen section evaluation of cervical conization specimens. J Reprod Med 1986;31:11-14

8. TORRES JE, MOORMAN J, SHIU A et al. - Colposcopically directed conization for frozen-section examination in the management of cervical intraepithelial neoplasia. J Reprod Med 1983;28:123 125.

9. PATERSON-BROWN S, CHAPPATTE OA, CLARK SK et al. - The significance of cone biopsy resection margins. Gynecol Oncol 1992;46:182-185

Received for publication on March 19, 2001 